\title{
Locus Coeruleus Integrity from 7T MRI Relates to Apathy and Cognition in Parkinson's Disease and Progressive Supranuclear Palsy
}

\author{
Rong Ye, $\mathrm{PhD}^{1^{*}}$, Claire O'Callaghan, $\mathrm{PhD}^{2,3^{*}}$, Catarina Rua, $\mathrm{PhD}^{1}$ Frank H. Hezemans, \\ $\mathrm{PhD}^{1,4}$, Negin Holland, MRCP ${ }^{1}$, Maura Malpetti, $\mathrm{PhD}^{1}$, P. Simon Jones, $\mathrm{MSc}^{1}$, Roger A. \\ Barker, MRCP, $\mathrm{PhD}^{5,6}$, Caroline H. Williams-Gray, MRCP, $\mathrm{PhD}^{5}$, Trevor W. Robbins, \\ $\mathrm{PhD}^{7,8}$, Luca Passamonti, MRCP, $\mathrm{PhD}^{1,9^{* *}}$, James Rowe, FRCP, $\mathrm{PhD}^{1,4^{* *}}$
}

1. Department of Clinical Neurosciences and Cambridge University Hospitals NHS Trust, University of Cambridge, UK

2. Brain and Mind Centre and School of Medical Sciences, Faculty of Medicine and Health, University of Sydney, Australia

3. Department of Psychiatry, University of Cambridge, UK

4. MRC Cognition and Brain Sciences Unit, University of Cambridge, UK

5. John van Geest Centre for Brain Repair, Department of Clinical Neurosciences, University of Cambridge, Cambridge, UK

6. Wellcome Trust - Medical Research Council Stem Cell Institute, University of Cambridge, Cambridge, UK

7. Department of Psychology, University of Cambridge, UK

8. Behavioural and Clinical Neuroscience Institute, University of Cambridge, UK

9. Istituto di Bioimmagini e Fisiologia Molecolare, Consiglio Nazionale delle Ricerche, Italy

*equal contribution **equal senior contribution

\section{Corresponding authors:}

Rong Ye

Herchel Smith Building for Brain and Mind

Sciences

Forvie Site, Robinson Way, Cambridge

CB2 0SZ

United Kingdom

+44(0) 1223764047

ronye.uk@gmail.com
Claire O'Callaghan

Brain and Mind Centre

94 Mallett Street, Camperdown NSW 2050

Australia

+61 (02) 93510702

claire.ocallaghan@sydney.edu.au 
medRxiv preprint doi: https://doi.org/10.1101/2021.04.19.21255762; this version posted April 27, 2021. The copyright holder for this preprint

\begin{abstract}

\section{Background and Objectives}

The loss of noradrenergic neurons in the locus coeruleus (LC) contributes to various cognitive and neuropsychiatric symptoms in Parkinson's disease (PD) and progressive supranuclear palsy (PSP). The spatial precision of in vivo LC imaging is improved using a magnetisation transfer sequence combined with ultra-high field 7T MRI. This study aimed to test the sensitivity of LC imaging in PD and PSP, to characterise the spatial pattern of LC atrophy in patients, and its relationship to cognition and apathy.
\end{abstract}

\title{
Methods
}

This cross-sectional observational study recruited patients with idiopathic PD, probable PSPRichardson's syndrome and age-matched healthy controls (HC) via specialist clinics and volunteer registries. All participants underwent clinical assessments for cognition and apathy, and high-resolution $\left(0.08 \mathrm{~mm}^{3}\right)$ LC scans. To quantify LC integrity, the contrast-to-noise ratio (CNR) relative to a pons reference region was calculated and extracted using a probabilistic atlas. Subregional mean CNRs were summarised to test group differences and to correlate LC integrity with apathy and cognition scores. LC clusters were identified to confirm the spatial pattern of the effect (threshold free cluster enhancement, 10000 permutations, $p<0.05$, corrected for family-wise error).

\section{Results}

Twenty-five patients with PD, 14 with PSP and 24 controls with completed dataset were included in the study. Patients with PSP were more impaired on global cognition and apathy scores, compared to controls and PD. Clusters with reduced contrast were observed in the caudal LC for both PD and PSP patients relative to controls (HC>PD, right caudal LC, 37 voxels; HC>PSP, bilateral caudal LC, 206 voxels). PSP and PD patients showed similar levels of LC degeneration, but this was more extensive in PSP. Across both disease groups, LC integrity was associated with cognitive performance (MoCA: $\mathrm{F}(1,37)=5.339, p=0.027$, bilateral LC, 200 voxels; ACE-R: $\mathrm{F}(1,37)=4.297, p=0.045$, left LC, 70 voxels) and apathy (Apathy Scale: $\mathrm{F}(1,37)=4.335, p=0.044$, left LC, 99 voxels).

\section{Discussion}

We confirm the sensitivity of 7T LC imaging to detect sub-regional LC changes in PD and PSP. The relationship between LC integrity and non-motor symptoms highlights the potential for noradrenergic therapeutic strategies to ameliorate cognitive and behavioural features of PD and PSP. 
medRxiv preprint doi: https://doi.org/10.1101/2021.04.19.21255762; this version posted April 27, 2021. The copyright holder for this preprint

\section{Introduction}

Parkinson's disease (PD) and progressive supranuclear palsy (PSP) result from distinct pathologies, yet they share a number of non-motor symptoms. These include executive dysfunction and neuropsychiatric features, with apathy ${ }^{1-3}$. While the causes of cognitive and neuropsychiatric symptoms in these diseases are multi-factorial, there is increasing evidence that noradrenergic dysfunction plays a prominent role ${ }^{4-7}$.

In both PD and PSP, the noradrenergic locus coeruleus is a site of selective vulnerability, undergoing early and severe pathological changes along its rostrocaudal axis ${ }^{8-11}$. Highly collateralised projections enable the locus coeruleus to release noradrenaline in widespread brain regions. The effect of noradrenaline at target regions is to alter the gain of neurons and facilitate reorganisation of functional networks ${ }^{12}{ }^{13}$. Through these actions, noradrenaline influences many cognitive functions, in particular promoting attentional focus and flexible shifting between goal-directed behaviours ${ }^{14}$. In PD and PSP, vulnerability of locus coeruleus neurons and consequent loss of noradrenergic projections has a wide-ranging impact on cognition and behaviour ${ }^{15}$.

We propose that noradrenergic deficits are determinants of cognitive and behavioural impairments in PD and PSP, and are therefore a promising treatment target for cognitive and neuropsychiatric symptoms. However, individual differences in brain structure and neurochemistry determine a patient's response to noradrenergic treatment, with a non-linear (U-shaped) pattern similar to dopaminergic and serotonergic interventions $6,7,16,17$. Specifically, it is proposed that an individual's need for - and response to - noradrenergic treatment depends on the state of their locus-coeruleus noradrenergic system.

Progress in noradrenergic therapeutics has been hindered by the need for in vivo characterisation of individuals' locus coeruleus degeneration. The locus coeruleus is small and elongated $(\sim 1 \times 16 \mathrm{~mm})$ with few neurons ( 50,000 in humans), which challenges standard imaging techniques. Specialised magnetisation-transfer sequences have been developed, that are sensitive to the intrinsic contrast generated by neuromelanin-rich noradrenergic cells of the locus coeruleus ${ }^{18,19}$. These correlate with the density of neuromelanin-positive neurons in the locus coeruleus ${ }^{20,21}$, providing a biomarker of locus coeruleus degeneration ${ }^{22}$ that confirms reductions in $\mathrm{PD}$ and $\mathrm{PSP}^{23,24}$. Such sequences are 
medRxiv preprint doi: https://doi.org/10.1101/2021.04.19.21255762; this version posted April 27, 2021. The copyright holder for this preprint

most sensitive at ultra-high field 7T MRI ${ }^{25,26}$, providing both enhanced contrast-to-noise and improved spatial resolution.

Here, we test the hypothesis that apathy and cognitive function correlate with the integrity of the locus coeruleus in PD and PSP, exploiting ultra-high field neuromelanin-sensitive 7T MRI. The high resolution $\left(0.08 \mathrm{~mm}^{3}\right)$ enabled localisation of degeneration to sub-regions of the locus coeruleus. Given the prominent role the locus coeruleus-noradrenergic system plays in cognition and goal-directed behaviours, we predict that clinical assessments of cognition and apathy will relate to locus coeruleus integrity, with a rostro-caudal gradient of degeneration.

\section{Methods}

\section{Participants}

Sixty-six participants aged between 50-80 years were recruited, including 25 patients with idiopathic PD, 15 with PSP-Richardson's syndrome and 26 age- and sex-matched healthy controls. Two controls and one PSP patient were excluded due to abnormal structural images or missing data (see below). Patients with idiopathic Parkinson's disease were recruited via the University of Cambridge Parkinson's Disease Research Clinic and the Parkinson's UK volunteer network, and met the United Kingdom Parkinson's Disease Society Brain Bank criteria for PD diagnosis. Patients with PSP were recruited from a tertiary specialist clinic at the Cambridge University Centre for Parkinson-plus, with probable PSP-Richardson's syndrome. Healthy controls were recruited from local volunteer panels. No controls were using psychoactive medications and exclusion criteria for all participants included current or history of ischaemic or haemorrhagic stroke, severe co-morbidity, and any contraindications to 7T MRI. None of the PD patients had impulse control disorders, based on clinical impression and the Questionnaire for Impulsive-Compulsive Disorders in Parkinson's Disease screening tool. The patients were not demented, based on mini-mental state examination (score $>26)^{27}$ and clinical impression. All PD patients and 10/14 PSP patients were taking dopaminergic medications, and Levodopa equivalent daily dose (LEDD) scores were calculated. Demographic results and clinical features are provided in Table 1. 
medRxiv preprint doi: https://doi.org/10.1101/2021.04.19.21255762; this version posted April 27, 2021. The copyright holder for this preprint

\section{Standard Protocol Approvals, Registrations, and Patient Consents}

The study was approved by the local Cambridge Research Ethics Committees (REC reference: 10/H0308/34) and all participants provided written informed consent according to the Declaration of Helsinki.

\section{Clinical Assessments}

Participants completed assessments of global cognition (Mini-mental status examination; MMSE, Addenbrooke's Cognitive Examination Revised; ACE-R and Montreal Cognition Assessment; MoCA) and self-rated mood/behaviour questionnaires: the Apathy Scale ${ }^{28}$, the Barratt Impulsiveness Scale ${ }^{29}$, Hamilton Anxiety and Depression Scales (noting that several questions are probing apathy not low mood), and the REM Sleep Behaviour Disorder Screening Questionnaire (RBDSQ). Higher scores on these questionnaires indicate more severe impairment. For PD and PSP patients, motor severity was assessed using the Movement Disorder Society Unified Parkinson's Disease Rating Scale motor section (MDSUPDRS-III). PSP patients additionally underwent the PSP Rating Scale (PSPRS). For both measures, higher scores are consistent with more severe motor symptoms. Patients underwent MRI and clinical assessments on their regular medications (see Table 1).

\section{MRI Acquisition}

Participants underwent MR scans on a 7T Magnetom Terra (Simens, Erlangen, Germany) with a 32-channel head coil (Nova Medical, Wilmington, USA). Two controls had incidental structural abnormalities discovered on diagnostic scans. The imaging data for one PSP patient was missing due to coil reconstruction failure. These participants were excluded from the following analyses. The locus coeruleus was imaged using a sensitive 3-D magnetisation transfer (MT) weighted sequence ${ }^{25}$ at high resolution $\left(0.4 \times 0.4 \times 0.5 \mathrm{~mm}^{3}\right)$, following the same protocol in previous studies ${ }^{7,26}$. A high resolution T1-weighted structural image $(0.7$ $\mathrm{mm}$ isotropic) was acquired using MP2RAGE sequence with the UK7T Network harmonised protocol $^{30}$. For the MT-weighted sequence, 112 oblique, high-resolution, axial slices were placed perpendicular to the long axis of the brainstem, covering both midbrain and pons. A train of $20 \mathrm{MT}$ pulses at $6.72 \mathrm{ppm}$ off resonance were applied followed by a turbo-flash readout $\left(\mathrm{TE}=4.08 \mathrm{~ms}, \mathrm{TR}=1251 \mathrm{~ms}\right.$, flip-angle $=8^{\circ}$, voxel size $=0.4 \times 0.4 \times 0.5 \mathrm{~mm}^{3}, 6 / 8$ phase and slice partial Fourier, bandwidth $=140 \mathrm{~Hz} / \mathrm{px}$, no acceleration, 14.3\%oversampling, TA $\sim 7 \mathrm{~min}$ ). The MT sequence was repeated twice and averaged offline to 
medRxiv preprint doi: https://doi.org/10.1101/2021.04.19.21255762; this version posted April 27, 2021. The copyright holder for this preprint

enhance the signal-to-noise ratio. An additional scan without MT pre-saturation ( $\left.\mathrm{MT}_{\text {off }}\right)$ was acquired for registration purposes. A high resolution T1-weighted structural image was acquired using MP2RAGE sequence: $\mathrm{TE}=2.58 \mathrm{~ms}$, TR $=3500 \mathrm{~ms}, \mathrm{BW}=300 \mathrm{~Hz} / \mathrm{px}$, voxel size $=0.7 \times 0.7 \times 0.7 \mathrm{~mm}^{3}, \mathrm{FoV}=224 \times 224 \times 157 \mathrm{~mm}^{3}$, acceleration factor $(\mathrm{A}>>\mathrm{P})=3$, flip angles $=5 / 2^{\circ}$ and inversion times $(\mathrm{TI})=725 / 2150 \mathrm{~ms}$ for the first $/$ second images .

\section{Locus Coeruleus Integrity Estimation}

To limit potential confounds in standard intensity-based segmentation and increase the sensitivity, an atlas-based segmentation approach was adopted to estimate LC integrity using a $5 \%$ probabilistic LC atlas in the standard space, generated from an independent $7 \mathrm{~T}$ data of 29 older healthy volunteers ${ }^{7}$. The MT images were co-registered to the high-resolution $(0.5$ mm isotropic) ICBM152 2009b template following a T1-driven, intra-modality coregistration pipeline using ANTs (v2.2.0) ${ }^{26}$. In summary, MT images were off-line bias field corrected and averaged; the roadmap used for image standardisation were generated using registration parameters estimated in the following steps (in order): $\mathrm{MT}_{\text {off }}$ to MT, individual $\mathrm{T} 1$ to $\mathrm{MT}_{\text {off }}$, individual T1 to T1 study-wise group template, and T1 group template to ICBM152 template. The standardisation of MT images was completed by applying all the transformation parameters in one step. Voxelwise contrast-to-noise ratio (CNR) of the LC was computed against a pontine reference region using the difference between a given voxel and the mean intensity of the reference region divided by the standard deviation of the reference signals. The LC mask was applied on CNR maps to extract averaged contrast for each slice, three equidistantly subdivided regions (rostral, central and caudal), left and right LC, and the whole structure.

Potential confounds that might affect MT signals were explicitly measured and compared across groups, including pons volumes and registration accuracy. FreeSurfer (v6.0.0) was used for segmenting and estimating volumes of individual brainstem substructures from their MP2RAGE images for quality assurance. Pairwise Dice Similarity Coefficients (DSC) between individual (I) coregistered and standard (S) pons were calculated with $\mathrm{DSC}=2(\mathrm{I} \cap \mathrm{S}) /(\mathrm{I}+\mathrm{S})$ to provide the measurement of registration accuracy. 
medRxiv preprint doi: https://doi.org/10.1101/2021.04.19.21255762; this version posted April 27, 2021. The copyright holder for this preprint

\section{Statistical Analyses}

Statistical analyses were performed in JASP (v0.11.1) and R (version 3.6.1). Group differences in clinical assessments and LC contrast across the subregions were tested using ANOVA and post hoc tests for controls and patients. The relationships between regional mean LC contrast and clinical assessments were specifically tested in patient groups with linear regression models with clinical scores as the dependent variable and LC CNR as fixed effect. Additional linear models were tested with age as a covariate of no interest and to test the group interaction within patient groups. We report the results for the hypothesis testing with a significance level of $p=0.05$. The effect size was estimated using Cohen's $\mathrm{d}$ in pairwise tests and $\mathrm{R}^{2}$ for linear regression models. The $95 \%$ confidence interval (CI) was provided for variables.

\section{Voxelwise Analyses}

Voxelwise analyses provide a more sensitive and spatially more accurate localisation for the LC group differences and clinical correlations, as averaged CNR is insensitive to voxel-byvoxel variations in LC integrity. The co-registered CNR maps were smoothed with a $1 \mathrm{~mm}$ FWHM Gaussian kernel, masked by the 5\% 7T LC atlas, then subjected to general linear models for testing group differences. Relationships with clinical variables were assessed by regression models where clinical scores were mean-centred across patient groups. Voxelwise analyses used the randomise function in FSL (v6.0.0). A threshold free cluster enhancement (TFCE) method was adopted for cluster inference combined with permutation tests (10000 iterations). Analogous regression models used age included as covariate of no interest. The family-wise error $(\mathrm{FWE})$ corrected p-value $(<0.05)$ was used to determine significant clusters.

\section{Data Availability}

The MT and MP2RAGE data used in this study are available for non-commercial academic purposes upon request.

\section{Results}

\section{Demographics and Clinical Assessment}

Demographics and clinical data are summarised in Table 1. Controls were age- and sexmatched to patient groups. Patients with PSP had fewer years of education compared to controls, and they were more impaired on the MMSE, MoCA, ACE-R, Apathy Scale and 
medRxiv preprint doi: https://doi.org/10.1101/2021.04.19.21255762; this version posted April 27, 2021. The copyright holder for this preprint

HADS-depression assessments relative to both controls and PD. Patients with PD had higher LEDD and RBDSQ scores than PSP.

\section{Locus Coeruleus Group Differences}

LC integrity assessment benefited from the atlas-based approach, which had clear advantages over classic segmentation-based methods. Pathology-related signal reduction in the LC is accompanied by increased segmentation failure and reduced spatial precision, leading to inflated contrast estimation. Using regional averaged LC contrast, there were group differences in the caudal subregion $(\mathrm{F}(2,60)=4.05, p=0.02)$ between PSP patients and controls ( $p_{\text {tukey }}=0.02$, Cohen's $\mathrm{d}=0.89,95 \%$ CI [0.2 2.92]), but not for PD versus controls $\left(p_{\text {tukey }}=0.16\right.$, Cohen's d=0.59, 95\% CI [-0.26 2.06]) or PD versus PSP ( $p_{\text {tukey }}=0.48$, Cohen's $d=0.36,95 \%$ CI $[-0.692 .01])$. There was no difference across the three groups in whole-LC contrast $(\mathrm{F}(2,60)=1.759, p=0.181$ ) or other subregions (rostral: $\mathrm{F}(2,60)=1.066, p=0.351$; central: $\mathrm{F}(2,60)=1.293, p=0.282)$. There was no significant effect of lateralisation on whole-LC contrast $(\mathrm{F}(1,60)=3.802, p=0.06$, left vs right: Cohen's $\mathrm{d}=0.32,95 \% \mathrm{CI}[0.030 .27])$, or group $\times$ lateralisation interaction $(\mathrm{F}(2,60)=2.637, p=0.08)$, although in view of the weak trend we tested and confirmed a marginal left-lateralised effect of LC contrast only in PD (left > right: $p_{\text {holm }}=0.05$, Cohen's $\mathrm{d}=0.38,95 \%$ CI $\left.[<0.010 .56]\right)$. The whole-LC contrast did not differ by $\operatorname{sex}(\mathrm{t}(62)=0.7, p=0.48$, Cohen's $\mathrm{d}=0.18,95 \%$ CI $[-0.690 .33])$. There was no linear nor quadratic relationship detected between $\mathrm{LC}$ contrast and age (linear: $\mathrm{F}(1,61)=0.84, \mathrm{R}^{2}=0.01$, $\beta=-0.12, p=0.36,95 \%$ CI [-0.09 0.03]; quadratic: $\mathrm{F}(2,60)=1.55, \mathrm{R}^{2}=0.05, \beta_{\mathrm{age}}=2.59, p=0.16$, $95 \%$ CI [-0.26 1.55], $\beta_{\mathrm{age}}^{2}=-2.71, p=0.14,95 \%$ CI [-0.01 0.002]).

To ensure that the caudal findings were not driven by varied noise levels in subregions or across groups, we compared the signal-to-noise ratio (SNR) for three subregions and examined the subregion $\times$ group interaction. The SNR differed between subregions $(\mathrm{F}(2,120)=13.02, p<0.001)$. However, the effect was only evident in the rostral $\mathrm{LC}\left(\mathrm{LC}_{\mathrm{rostral}}>\right.$ $\mathrm{LC}_{\text {central }}: p_{\text {holm }}<0.001$, Cohen's d=0.68, 95\% CI [2.19 5.85]; $\mathrm{LC}_{\text {rostral }}>\mathrm{LC}_{\text {caudal }}: p_{\text {holm }}=0.003$, Cohen's d=0.42, 95\% CI [0.93 6.08]), whereas SNRs of central and caudal LC did not differ ( $p_{\text {holm }}=0.525$, Cohen's d=0.08, 95\% CI [-1.47 2.49]). There was no group by subregion SNR interaction $(\mathrm{F}(4,120)=2.22, p=0.07)$. Furthermore, there was no group difference observed for pons volumes $(\mathrm{F}(2,59)=2.27, p=0.11)$ or pons registration accuracy (DSC Mean $\pm \mathrm{SD}$ : $0.875 \pm 0.02$, range: $0.743-0.89, \mathrm{~F}(2,60)=1.388, p=0.258)$, indicating that the contrast 
medRxiv preprint doi: https://doi.org/10.1101/2021.04.19.21255762; this version posted April 27, 2021. The copyright holder for this preprint

difference in the LC was not attributed to these potential confounds. Adding both caudal LC SNR and registration accuracy did not meaningfully change the caudal findings in patients $\left(\mathrm{F}(2,56)=4.63, p=0.01\right.$; HC vs PSP: $p_{\text {tukey }}=0.01$, Cohen's d=1, 95\% CI [0.37 3.14]; HC vs PD: $p_{\text {tukey }}=0.38$, Cohen's $\mathrm{d}=0.46,95 \%$ CI [-0.55 1.96]; PD vs PSP: $p_{\text {tukey }}=0.2$, Cohen's $\mathrm{d}=0.56,95 \%$ CI $[-0.42 .5])$.

Voxelwise analyses revealed clusters with significantly reduced contrast (threshold free cluster enhancement, $p<0.05$, FWE-corrected) in both disease groups compared to controls (Table 2). A small cluster with reduced contrast was identified for PD patients in the right caudal LC (Fig 1C, 37 voxels) whereas PSP patients had extensive bilateral caudal damage in the LC (Fig 1D, 206 voxels). There was no group difference between PD and PSP by voxelwise analysis.

\section{Locus Coeruleus Integrity and Clinical Assessments in Patients}

MoCA performance was associated with whole LC contrast (Fig $2 \mathrm{~A}, \mathrm{~F}(1,37)=5.34, \mathrm{R}^{2}=0.13$, $\left.\beta_{\mathrm{LC}}=0.36, p=0.03,95 \% \mathrm{CI}[0.081 .22]\right)$, and the ACE-R and Apathy scores were associated with left LC contrast values (ACE-R: Fig $2 \mathrm{~B}, \mathrm{~F}(1,37)=4.3, \mathrm{R}^{2}=0.1, \beta_{\mathrm{LC}}=0.32, p=0.04,95 \%$ CI [0.03 2.18]; Apathy Scale: Fig 2C, $\mathrm{F}(1,37)=4.34, \mathrm{R}^{2}=0.08, \beta_{\mathrm{LC}}=-0.29, p=0.04,95 \%$ CI [$2.69-0.04])$. A significant group $\times$ LC interaction was detected only for Apathy scores ( $p=0.01)$, where the effect was present in PSP $(\mathrm{F}(1,12)=5.75, p=0.03,95 \%$ CI $[-4.39-0.21])$ but not significant for the PD group $(\mathrm{F}(1,23)=0.93, p=0.34,95 \%$ CI [-0.8 2.19]). There was no group effect observed for the relationships between LC integrity and MoCA $(p=0.93)$ or ACE-R ( $p=0.67)$ assessments. Including age as the nuisance covariate did not meaningfully change the relationship between $\mathrm{LC}$ contrast and $\operatorname{MoCA}\left(\mathrm{F}(2,36)=3.71, \mathrm{R}^{2}=0.17, \beta_{\mathrm{LC}}=0.33\right.$, $p=0.04,95 \%$ CI [0.03 1.16], $\beta_{\text {Age }}=-0.21, p=0.17,95 \%$ CI [-0.24 0.04]). Marginal effect of the LC contrast was observed on ACE-R $\left(\mathrm{F}(2,36)=3.75, \mathrm{R}^{2}=0.17, \beta_{\mathrm{LC}}=0.28, p=0.08,95 \%\right.$ CI [$\left.0.112 .02], \beta_{\mathrm{Age}}=-0.27, p=0.09,95 \% \mathrm{CI}[-0.50 .04]\right)$ and $\mathrm{AS}\left(\mathrm{F}(2,36)=2.2, \mathrm{R}^{2}=0.11, \beta_{\mathrm{LC}}=-0.31\right.$, $p=0.06,95 \%$ CI $[-2.680 .04], \beta_{\text {Age }}=0.06, p=0.39,95 \%$ CI [-0.28 0.41]) when adding age as the covariate.

Across all patients, the LC contrast was not associated with UPDRS motor scores $\left(\mathrm{F}(1,37)=0.09, \mathrm{R}^{2}<0.01, \quad \beta=-0.02, \quad p=0.77,95 \%\right.$ CI $\left.[-2.061 .78]\right)$ or disease duration $\left(\mathrm{F}(1,37)=0.02, \mathrm{R}^{2}<0.01, \beta=-0.05, p=0.9,95 \% \mathrm{CI}[-0.60 .45]\right)$. A marginally significant 
medRxiv preprint doi: https://doi.org/10.1101/2021.04.19.21255762; this version posted April 27, 2021. The copyright holder for this preprint

relationship between left LC contrast values and BIS scores was observed $(F(1,37)=3.87$, $\left.\mathrm{R}^{2}=0.08, \beta=-0.28, p=0.06,95 \% \mathrm{CI}[-3.740 .05]\right)$. For cases with PSP, the LC contrast was not correlated with the PSPRS scores $\left(\mathrm{F}(1,12)=1.5, \mathrm{R}^{2}=0.11, \beta=-0.33, p=0.24,95 \%\right.$ CI $[-3.69$ $1.03])$.

A voxelwise analysis would have advantages for detecting and localising the effect of LC in cognition and apathy, if there are localised effects or if the arbitrary division of the LC into three parts did not correspond to neuropathological divisions. The voxel-wise results confirmed bilateral LC clusters were positively correlated with MoCA scores (Fig 2D; TFCE, FWE-corrected $p<0.05$ ), and higher contrast in the left caudal LC clusters was positively correlated with ACE-R scores (Fig 2E): these positive correlations indicate preserved LC integrity was associated with better cognitive performance. Consistently, the left central and caudal LC clusters were negatively correlated with Apathy (Fig 2F), that is, reduced LC integrity was associated with worse apathy. The details for the LC clusters associated with cognition and apathy were summarised in Table 2. Adding age as a covariate of no interest did not meaningfully change the results of voxelwise analyses.

\section{Discussion}

Using ultra-high field 7T magnetisation-transfer imaging, we confirm in vivo loss of locus coeruleus integrity in two neurodegenerative diseases (PD and PSP) that have well established locus coeruleus pathology at post mortem. We confirm the regionally specific pattern of predominantly caudal locus coeruleus changes in PD and PSP, which was associated with cognitive impairment and apathy. These findings highlight the importance of the locus coeruleus-noradrenaline system in cognitive and behavioural features of these diseases. They demonstrate the utility of neuromelanin-sensitive imaging at ultra-high field to measure the locus coeruleus in neurodegenerative disease, which we suggest will be an important biomarker for use in future clinical trials, where patients could be stratified according to locus coeruleus integrity ${ }^{7,26}$.

The simple group-wise effect of PD and PSP on the locus coeruleus was most apparent in the caudal subregion. This rostro-caudal gradient has been noted in some neuropathological studies of $\mathrm{PD}^{31}$, although not all $^{32}$. More severe caudal degeneration in conditions with prominent behavioural and motor features, such as PD and PSP, is consistent with the 
topographic organisation of the locus coeruleus where caudal cells project to the basal ganglia $^{33,34}$, while Alzheimer's disease, Down's syndrome ${ }^{32}$, and healthy ageing ${ }^{35}$ have been associated with greater cell loss from the rostral locus coeruleus. In our PD and PSP participants, the relationship of LC signal to behavioural (Apathy scale) and cognitive (e.g., MoCA) change was not confined to caudal regions, but extended to mid and rostral LC respectively (Fig 2).

Whereas the caudal locus coeruleus has some topographic specific projections to subcortical regions, rostral projections preferentially target prefrontal cortex ${ }^{33,34}$, consistent with their role in diverse cognitive functions. Locus coeruleus degeneration and reduced noradrenaline in neurodegenerative disease is linked with a higher risk of progression to dementia ${ }^{5,36}$, and faster cognitive decline in older adults ${ }^{37,38}$. The correlation of apathy to LC integrity - most clearly in the PSP group - is in keeping with extensive human and preclinical evidence linking goal directed behaviour with the noradrenergic system ${ }^{14,39,40}$. Our results highlight that whilst cognitive and motivation deficits in neurodegenerative disease have multifactorial causes, the locus coeruleus-noradrenaline system plays a key role via its widespread modulation of target structures supporting these processes.

Cognitive decline and disorders of goal directed behaviour, including the co-occurrence of both apathy and impulsivity ${ }^{41,42}$, are common in both PD and PSP. The link we have shown between locus coeruleus integrity and these non-motor symptoms supports the rationale for noradrenergic therapies in selected patients. Preliminary work in PD suggests that the noradrenergic reuptake inhibitor atomoxetine can improve goal directed behaviour ${ }^{6}$ and that drug responsivity depends on locus coeruleus integrity ${ }^{7}$. The ability to detect localised changes in the locus coeruleus that we have demonstrated here in PD and PSP, supports the hypothesis that this technique could be used to stratify patients in future clinical trials of noradrenergic therapy in neurodegenerative disease.

The current study exploits the benefit of ultra-high field 7T MRI, for assessment of the locus coeruleus in vivo. The short imaging sequence ${ }^{25}$ was well-tolerated in a clinical setting. For locus coeruleus signal extraction, we advanced a cross-modality co-registration pipeline and an atlas-based approach, to maximise spatial precision and avoid estimation biases that occur with classic segmentation-based methods. Potential confounds specific to locus coeruleus imaging were also controlled and explicitly tested, including the consistency of noise level 
along the rostrocaudal axis and the effect of age. Moreover, the spatial localisation of effects was further improved by voxelwise analyses that exploited the high resolution afforded by $7 \mathrm{~T}$ MRI. Not only do these advances allow for more accurate locus coeruleus quantification, they permit the localisation of changes to locus coeruleus sub-regions, which have previously been identified in post mortem studies ${ }^{32,43,44}$. The histological validation of neuromelaninsensitive imaging ${ }^{20}$ provides additional evidence that the results we report here reflect the underlying pathological changes that have been observed at post mortem. Together, these findings pave the way for future clinical studies to investigate contributions of the locus coeruleus-noradrenaline system in the pathogenesis, progression and treatment of neurodegenerative diseases.

There is significant heterogeneity in the expression of motor, neuropsychiatric and cognitive features across both $\mathrm{PD}^{1}$ and $\mathrm{PSP}^{45}$. Locus coeruleus pathology may be more prominent in certain PD phenotypes, including patients with cognitive impairment or dementia ${ }^{46,47}$, depression ${ }^{24}$, and REM sleep behaviour disorder ${ }^{48}$. Future studies using ultra-high field locus coeruleus imaging in PD and PSP may focus on specific phenotypes, to define the role of regionally specific locus coeruleus changes in specific non-motor symptoms. For example, the caudal sub-region may be especially vulnerable as it lies adjacent to the $4^{\text {th }}$ ventricle, exposed to environmental insults from the cerebrospinal fluid ${ }^{49}$. Also, the caudal locus coeruleus receives projections from the vagal nerve via the nucleus of the solitary tract which might speculatively make it more vulnerable to transmission of misfolded proteins from the periphery $^{50}$. Future studies would be required to establish the relationship to peripheral molecular pathology.

\section{Conclusions}

The locus coeruleus is a site of selective vulnerability across neurodegenerative diseases, and is hypothesised to influence the development of some cognitive and behavioural symptoms ${ }^{15}$, ${ }^{22}$. We provide in vivo confirmation of locus coeruleus degeneration in Parkinson's disease and Progressive Supranuclear Palsy and demonstrate its association with cognition and apathy. Ultra-high field $7 \mathrm{~T}$ neuromelanin imaging is sensitive to the pathological changes in the locus coeruleus and its associated clinical features. This MRI technique can provide a valuable tool for investigating non-motor symptoms and stratifying patients in clinical trials of noradrenergic therapy. 
medRxiv preprint doi: https://doi.org/10.1101/2021.04.19.21255762; this version posted April 27, 2021. The copyright holder for this preprint (which was not certified by peer review) is the author/funder, who has granted medRxiv a license to display the preprint in perpetuity.

It is made available under a CC-BY 4.0 International license. 


\section{Acknowledgements}

This study was supported by Parkinson's UK (K-1702); the Cambridge Centre for ParkinsonPlus; the China Scholarship Council; a Neil Hamilton Fairley Fellowship from the Australian National Health and Medical Research Council (GNT1091310); a Cambridge Trust ViceChancellor's Award and Fitzwilliam College Scholarship; the Association of British Neurologists - Patrick Berthoud Charitable Trust (RG99368); the Medical Research Council (SUAG/051 G101400; MR/P01271X/1); James S. McDonnell Foundation 21st Century Science Initiative Scholar Award in Understanding Human Cognition; the Wellcome Trust (103838); a RCUK/UKRI Research Innovation Fellowship awarded by the Medical Research Council (MR/R007446/1); the NIHR Cambridge Clinical Research Facility and the NIHR Cambridge Biomedical Research Centre (BRC-1215-20014). For the purpose of open access, the author has applied a CC BY public copyright licence to any Author Accepted Manuscript version arising from this submission. The views expressed are those of the authors and not necessarily those of the NHS, the NIHR or the Department of Health and Social Care.

\section{Potential Conflicts of Interest}

The authors declared no conflict of interest. 
medRxiv preprint doi: https://doi.org/10.1101/2021.04.19.21255762; this version posted April 27, 2021. The copyright holder for this preprint

\section{References}

1. Kehagia AA, Barker RA, Robbins TW. Neuropsychological and clinical heterogeneity of cognitive impairment and dementia in patients with Parkinson's disease. Lancet Neurol 2010;9:1200-1213.

2. Aarsland D, Litvan I, Larsen JP. Neuropsychiatric symptoms of patients with progressive supranuclear palsy and Parkinson's disease. J Neuropsychiatry Clin Neurosci 2001;13:42-49.

3. Litvan I, Mega MS, Cummings JL, Fairbanks L. Neuropsychiatric aspects of progressive supranuclear palsy. Neurology 1996;47:1184-1189.

4. Passamonti L, Lansdall CJ, Rowe JB. The neuroanatomical and neurochemical basis of apathy and impulsivity in frontotemporal lobar degeneration. Curr Opin Behav Sci 2018;22:14-20.

5. Halliday GM, Leverenz JB, Schneider JS, Adler CH. The neurobiological basis of cognitive impairment in Parkinson's disease. Mov Disord 2014;29:634650 .

6. Ye Z, Altena $\mathrm{E}$, Nombela $\mathrm{C}$, et al. Improving response inhibition in Parkinson's disease with atomoxetine. Biol Psychiatry 2015;77:740-748.

7. O'Callaghan C, Hezemans FH, Ye R, et al. Locus coeruleus integrity and the effect of atomoxetine on response inhibition in Parkinson's disease. Brain 2021.

8. Braak H, Del Tredici K, Rub U, de Vos RA, Jansen Steur EN, Braak E. Staging of brain pathology related to sporadic Parkinson's disease. Neurobiol Aging 2003;24:197-211.

9. Surmeier DJ, Obeso JA, Halliday GM. Selective neuronal vulnerability in Parkinson disease. Nat Rev Neurosci 2017;18:101-113.

10. Dickson DW, Ahmed Z, Algom AA, Tsuboi Y, Josephs KA. Neuropathology of variants of progressive supranuclear palsy. Curr Opin Neurol 2010;23:394-400.

11. Kaalund SS, Passamonti L, Allinson KSJ, et al. Locus coeruleus pathology in progressive supranuclear palsy, and its relation to disease severity. Acta Neuropathol Commun 2020;8:11.

12. Bouret S, Sara SJ. Network reset: a simplified overarching theory of locus coeruleus noradrenaline function. Trends Neurosci 2005;28:574-582.

13. Aston-Jones G, Cohen JD. An integrative theory of locus coeruleusnorepinephrine function: adaptive gain and optimal performance. Annu Rev Neurosci 2005;28:403-450.

14. Poe GR, Foote S, Eschenko O, et al. Locus coeruleus: a new look at the blue spot. Nat Rev Neurosci 2020;21:644-659.

15. Holland N, Robbins TW, Rowe JB. The role of noradrenaline in cognition and cognitive disorders. Brain 2021.

16. Cools R, D'Esposito M. Inverted-U-shaped dopamine actions on human working memory and cognitive control. Biol Psychiatry 2011;69:e113-125. 
medRxiv preprint doi: https://doi.org/10.1101/2021.04.19.21255762; this version posted April 27, 2021. The copyright holder for this preprint

(which was not certified by peer review) is the author/funder, who has granted medRxiv a license to display the preprint in perpetuity.

It is made available under a CC-BY 4.0 International license .

17. Ye Z, Altena E, Nombela C, et al. Selective serotonin reuptake inhibition modulates response inhibition in Parkinson's disease. Brain 2014;137:11451155 .

18. Keren NI, Lozar CT, Harris KC, Morgan PS, Eckert MA. In vivo mapping of the human locus coeruleus. Neuroimage 2009;47:1261-1267.

19. Betts MJ, Cardenas-Blanco A, Kanowski M, Jessen F, Duzel E. In vivo MRI assessment of the human locus coeruleus along its rostrocaudal extent in young and older adults. Neuroimage 2017;163:150-159.

20. Keren NI, Taheri S, Vazey EM, et al. Histologic validation of locus coeruleus MRI contrast in post-mortem tissue. Neuroimage 2015;113:235-245.

21. Cassidy CM, Zucca FA, Girgis RR, et al. Neuromelanin-sensitive MRI as a noninvasive proxy measure of dopamine function in the human brain. Proc Natl Acad Sci U S A 2019;116:5108-5117.

22. Betts MJ, Kirilina E, Otaduy MCG, et al. Locus coeruleus imaging as a biomarker for noradrenergic dysfunction in neurodegenerative diseases. Brain 2019;142:2558-2571.

23. Ohtsuka C, Sasaki M, Konno K, et al. Differentiation of early-stage parkinsonisms using neuromelanin-sensitive magnetic resonance imaging. Parkinsonism Relat Disord 2014;20:755-760.

24. Wang J, Li Y, Huang $\mathrm{Z}$, et al. Neuromelanin-sensitive magnetic resonance imaging features of the substantia nigra and locus coeruleus in de novo Parkinson's disease and its phenotypes. Eur J Neurol 2018;25:949-e973.

25. Priovoulos N, Jacobs HIL, Ivanov D, Uludag K, Verhey FRJ, Poser BA. High-resolution in vivo imaging of human locus coeruleus by magnetization transfer MRI at 3T and 7T. Neuroimage 2018;168:427-436.

26. Ye R, Rua C, O'Callaghan $\mathrm{C}$, et al. An in vivo probabilistic atlas of the human locus coeruleus at ultra-high field. Neuroimage 2021;225:117487.

27. Martinez-Martin P, Falup-Pecurariu C, Rodriguez-Blazquez C, et al. Dementia associated with Parkinson's disease: applying the Movement Disorder Society Task Force criteria. Parkinsonism Relat Disord 2011;17:621-624.

28. Starkstein SE, Mayberg HS, Preziosi TJ, Andrezejewski P, Leiguarda R, Robinson RG. Reliability, validity, and clinical correlates of apathy in Parkinson's disease. J Neuropsychiatry Clin Neurosci 1992;4:134-139.

29. Patton JH, Stanford MS, Barratt ES. Factor structure of the Barratt impulsiveness scale. J Clin Psychol 1995;51:768-774.

30. Clarke WT, Mougin O, Driver ID, et al. Multi-site harmonization of 7 tesla MRI neuroimaging protocols. Neuroimage 2020;206:116335.

31. Bertrand E, Lechowicz W, Szpak GM, Dymecki J. Qualitative and quantitative analysis of locus coeruleus neurons in Parkinson's disease. Folia Neuropathol 1997;35:80-86.

32. German DC, Manaye KF, White CL, 3rd, et al. Disease-specific patterns of locus coeruleus cell loss. Ann Neurol 1992;32:667-676. 
medRxiv preprint doi: https://doi.org/10.1101/2021.04.19.21255762; this version posted April 27, 2021. The copyright holder for this preprint

(which was not certified by peer review) is the author/funder, who has granted medRxiv a license to display the preprint in perpetuity.

It is made available under a CC-BY 4.0 International license .

33. Loughlin SE, Foote SL, Bloom FE. Efferent projections of nucleus locus coeruleus: topographic organization of cells of origin demonstrated by threedimensional reconstruction. Neuroscience 1986;18:291-306.

34. Mason ST, Fibiger HC. Regional topography within noradrenergic locus coeruleus as revealed by retrograde transport of horseradish peroxidase. J Comp Neurol 1979;187:703-724.

35. Manaye KF, McIntire DD, Mann DM, German DC. Locus coeruleus cell loss in the aging human brain: a non-random process. J Comp Neurol 1995;358:79-87.

36. Weinshenker D. Long Road to Ruin: Noradrenergic Dysfunction in Neurodegenerative Disease. Trends Neurosci 2018;41:211-223.

37. Clewett DV, Lee TH, Greening S, Ponzio A, Margalit E, Mather M. Neuromelanin marks the spot: identifying a locus coeruleus biomarker of cognitive reserve in healthy aging. Neurobiol Aging 2016;37:117-126.

38. Jacobs HI, Wiese S, van de Ven V, Gronenschild EH, Verhey FR, Matthews PM. Relevance of parahippocampal-locus coeruleus connectivity to memory in early dementia. Neurobiol Aging 2015;36:618-626.

39. Varazzani C, San-Galli A, Gilardeau S, Bouret S. Noradrenaline and dopamine neurons in the reward/effort trade-off: a direct electrophysiological comparison in behaving monkeys. J Neurosci 2015;35:7866-7877.

40. Bouret S, Richmond BJ. Sensitivity of locus ceruleus neurons to reward value for goal-directed actions. J Neurosci 2015;35:4005-4014.

41. Scott BM, Eisinger RS, Burns MR, et al. Co-occurrence of apathy and impulse control disorders in Parkinson disease. Neurology 2020;95:e2769e2780.

42. Lansdall CJ, Coyle-Gilchrist ITS, Jones PS, et al. Apathy and impulsivity in frontotemporal lobar degeneration syndromes. Brain 2017;140:1792-1807.

43. Ehrenberg AJ, Nguy AK, Theofilas P, et al. Quantifying the accretion of hyperphosphorylated tau in the locus coeruleus and dorsal raphe nucleus: the pathological building blocks of early Alzheimer's disease. Neuropathol Appl Neurobiol 2017;43:393-408.

44. Chan-Palay V, Asan E. Alterations in catecholamine neurons of the locus coeruleus in senile dementia of the Alzheimer type and in Parkinson's disease with and without dementia and depression. J Comp Neurol 1989;287:373-392.

45. Respondek G, Stamelou M, Kurz C, et al. The phenotypic spectrum of progressive supranuclear palsy: a retrospective multicenter study of 100 definite cases. Mov Disord 2014;29:1758-1766.

46. Cash R, Dennis T, L'Heureux R, Raisman R, Javoy-Agid F, Scatton B. Parkinson's disease and dementia: norepinephrine and dopamine in locus ceruleus. Neurology 1987;37:42-46.

47. Li Y, Wang C, Wang J, et al. Mild cognitive impairment in de novo Parkinson's disease: A neuromelanin MRI study in locus coeruleus. Mov Disord 2019;34:884-892. 
48. Garcia-Lorenzo D, Longo-Dos Santos C, Ewenczyk C, et al. The coeruleus/subcoeruleus complex in rapid eye movement sleep behaviour disorders in Parkinson's disease. Brain 2013;136:2120-2129.

49. Matchett BJ, Grinberg LT, Theofilas P, Murray ME. The mechanistic link between selective vulnerability of the locus coeruleus and neurodegeneration in Alzheimer's disease. Acta Neuropathol 2021.

50. Wood H. New models show gut-brain transmission of Parkinson disease pathology. Nat Rev Neurol 2019;15:491. 
medRxiv preprint doi: https://doi.org/10.1101/2021.04.19.21255762; this version posted April 27, 2021. The copyright holder for this preprint (which was not certified by peer review) is the author/funder, who has granted medRxiv a license to display the preprint in perpetuity.

It is made available under a CC-BY 4.0 International license .

\section{Tables}

Table 1 Mean (standard deviation) for demographics and clinical assessments.

\begin{tabular}{|c|c|c|c|c|c|c|}
\hline & \multicolumn{3}{|c|}{ Descriptive } & \multicolumn{3}{|c|}{$p$ values for pairwise tests } \\
\hline & HC $(n=24)$ & $P D(n=25)$ & $\operatorname{PSP}(n=14)$ & $\begin{array}{c}\text { HC vs } \\
\text { PD }\end{array}$ & $\begin{array}{l}\text { HC vs } \\
\text { PSP }\end{array}$ & $\begin{array}{c}\text { PD vs } \\
\text { PSP }\end{array}$ \\
\hline Age (years) & $65.5(5.5)$ & $67.4(7.4)$ & $69.7(7.7)$ & 0.58 & 0.16 & 0.58 \\
\hline $\begin{array}{l}\text { Education } \\
\text { (years) }\end{array}$ & $14.8(3.1)$ & $14.1(2.3)$ & $12.3(2.8)$ & 0.6 & 0.02 & 0.13 \\
\hline Male/Female & $13 / 11$ & $18 / 7$ & $8 / 6$ & 0.2 & 0.86 & 0.35 \\
\hline MMSE & $29.75(0.53)$ & $29.52(0.65)$ & $28.5(1.74)$ & 0.69 & $<0.001$ & 0.007 \\
\hline MoCA & $28.58(1.44)$ & $27.96(1.88)$ & $24(3.94)$ & 0.63 & $<0.001$ & $<0.001$ \\
\hline ACER-total & $97.71(3.25)$ & $95.40(3.61)$ & $87.21(7.17)$ & 0.18 & $<0.001$ & $<0.001$ \\
\hline Apathy Scale & $10.38(5.25)$ & $12.44(5.43)$ & $20(9.49)$ & 0.5 & $<0.001$ & 0.003 \\
\hline BIS & $55.71(9.56)$ & $58.18(10.31)$ & $63.86(12.44)$ & 0.69 & 0.06 & 0.25 \\
\hline $\begin{array}{l}\text { HADS- } \\
\text { depression }\end{array}$ & $2.83(2.84)$ & $4.24(2.73)$ & $7.43(4.27)$ & 0.27 & $<0.001$ & 0.01 \\
\hline HADS-anxiety & $4.29(3.53)$ & $5.04(3.16)$ & $6.57(3.2)$ & 0.71 & 0.11 & 0.36 \\
\hline RBDSQ & - & $5.48(3.65)$ & $3.07(1.82)$ & - & - & 0.03 \\
\hline $\begin{array}{l}\text { Disease Duration } \\
\text { (years) }\end{array}$ & - & $5(3.05)$ & $4.24(2.68)$ & - & - & 0.44 \\
\hline LEDD & - & $644.3(499.36)$ & 323.57 (389.4) & & & 0.04 \\
\hline UPDRS-III & - & $28.36(11.98)$ & 33.07 (6.96) & - & - & 0.19 \\
\hline PSPRS & - & - & $30.79(9.11)$ & - & - & - \\
\hline
\end{tabular}

Group difference in sex was examined using chi-square test. A one-way ANOVA was used for group difference with post-hoc Tukey HSD $p$ values provided for pairwise comparisons. RBDSQ, disease duration and UPDRS-III were compared with independent samples t-test between PD and PSP. MMSE: Mini-Mental State Examination, MoCA: Montreal Cognition Assessment, ACER: Addenbrooke's Cognitive Examination Revised, BIS: Barratt Impulsiveness Scale, HADS: Hamilton Anxiety and Depression Scale, RBDSQ: REM Sleep Behaviours Screening Questionnaire, LEDD: Levodopa equivalent daily dose, UPDRS: Unified Parkinson's Disease Rating Scale, PSPRS: Progressive Supranuclear Palsy Rating Scale. Significant $p$ values ( $p<0.0016$, equivalent to $p<0.05$ with Bonferroni correction) are highlighted in bold. 
medRxiv preprint doi: https://doi.org/10.1101/2021.04.19.21255762; this version posted April 27, 2021. The copyright holder for this preprint (which was not certified by peer review) is the author/funder, who has granted medRxiv a license to display the preprint in perpetuity.

It is made available under a CC-BY 4.0 International license

Table 2 TFCE clusters for regression models and group comparisons (FWE-corrected p<0.05)

\begin{tabular}{lllllll}
\hline \multicolumn{4}{l}{ Coordinates of local maxima $(\mathrm{mm})$} & \multicolumn{2}{l}{$\begin{array}{l}\text { volume } \\
\left(\mathrm{mm}^{3}\right)\end{array}$} & $\mathrm{t}$ \\
\hline Regression & $\mathrm{x}$ & $\mathrm{y}$ & $\mathrm{z}$ & $\mathrm{voxel}$ & \\
MoCA & -3 & -38.5 & -22.5 & 116 & 14.5 & 2.9 \\
& 4.5 & -39.5 & -26.5 & 84 & 10.5 & 2.95 \\
ACE-R & -4 & -39.5 & -26 & 63 & 7.875 & 3.01 \\
& 4.5 & -39.5 & -26.5 & 3 & 0.375 & 3.23 \\
& 3.5 & -39 & -23.5 & 3 & 0.375 & 3.12 \\
& 2 & -37.5 & -19 & 1 & 0.125 & 3.2 \\
AS & -4.5 & -39 & -22.5 & 99 & 12.375 & 2.54 \\
\hline Regression with & & & & & & \\
Age covariate & & & & & & \\
MoCA & -3 & -38.5 & -22.5 & 68 & 8.5 & 2.92 \\
& 4.5 & -39.5 & -26.5 & 53 & 6.625 & 2.96 \\
ACE-R & -4 & -39.5 & -26 & 19 & 2.375 & 3.15 \\
& -2.5 & -38 & -19.5 & 1 & 0.125 & 3.47 \\
AS & -5 & -39.5 & -26 & 19 & 2.375 & 2.59 \\
& -4.5 & -39 & -22.5 & 7 & 0.875 & 2.78 \\
& -2.5 & -37.5 & -18 & 3 & 0.375 & 2.99 \\
& -3 & -38.5 & -24 & 2 & 0.25 & 2.58 \\
& -3 & -38 & -21.5 & 2 & 0.25 & 2.53 \\
\hline HC > PSP & -5 & -40 & -27.5 & 124 & 15.5 & 2.9 \\
& 3.5 & -39 & -25.5 & 82 & 10.25 & 2.92 \\
\hline
\end{tabular}


medRxiv preprint doi: https://doi.org/10.1101/2021.04.19.21255762; this version posted April 27, 2021. The copyright holder for this preprint (which was not certified by peer review) is the author/funder, who has granted medRxiv a license to display the preprint in perpetuity.

It is made available under a CC-BY 4.0 International license.

Figure 1
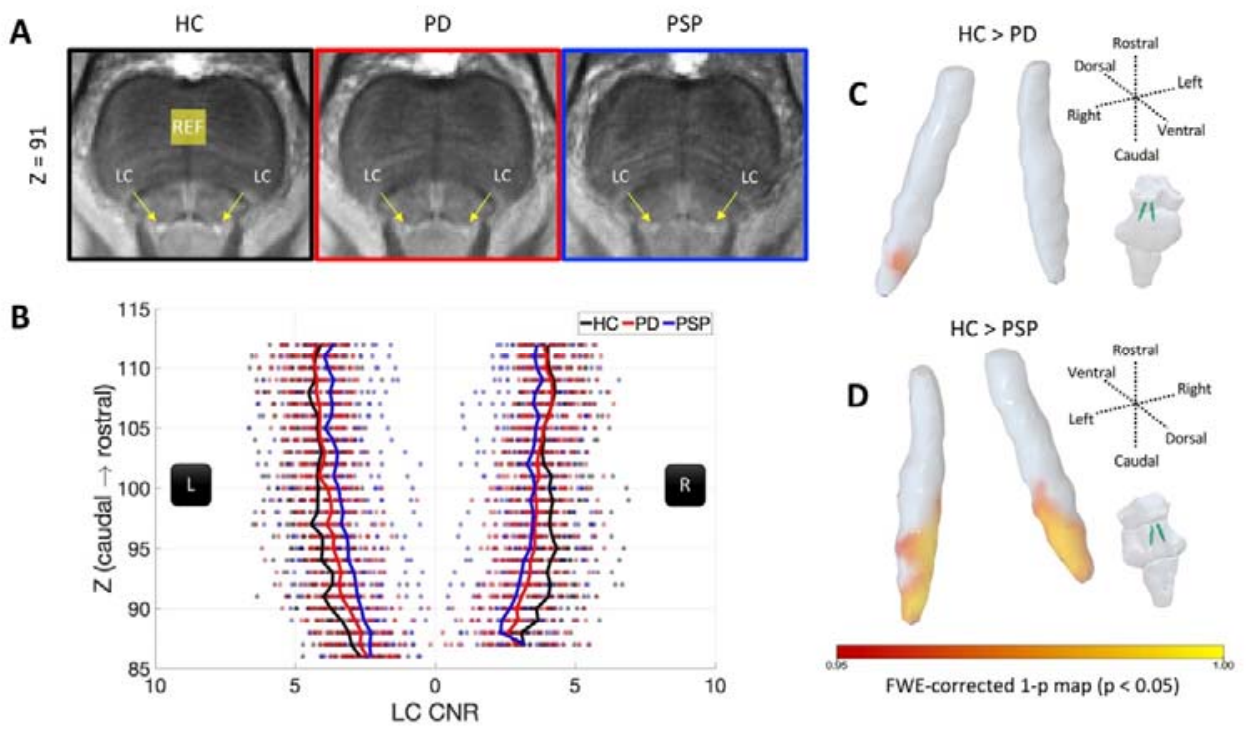

FWE-corrected 1-p map $(p<0.05)$

Figure 2
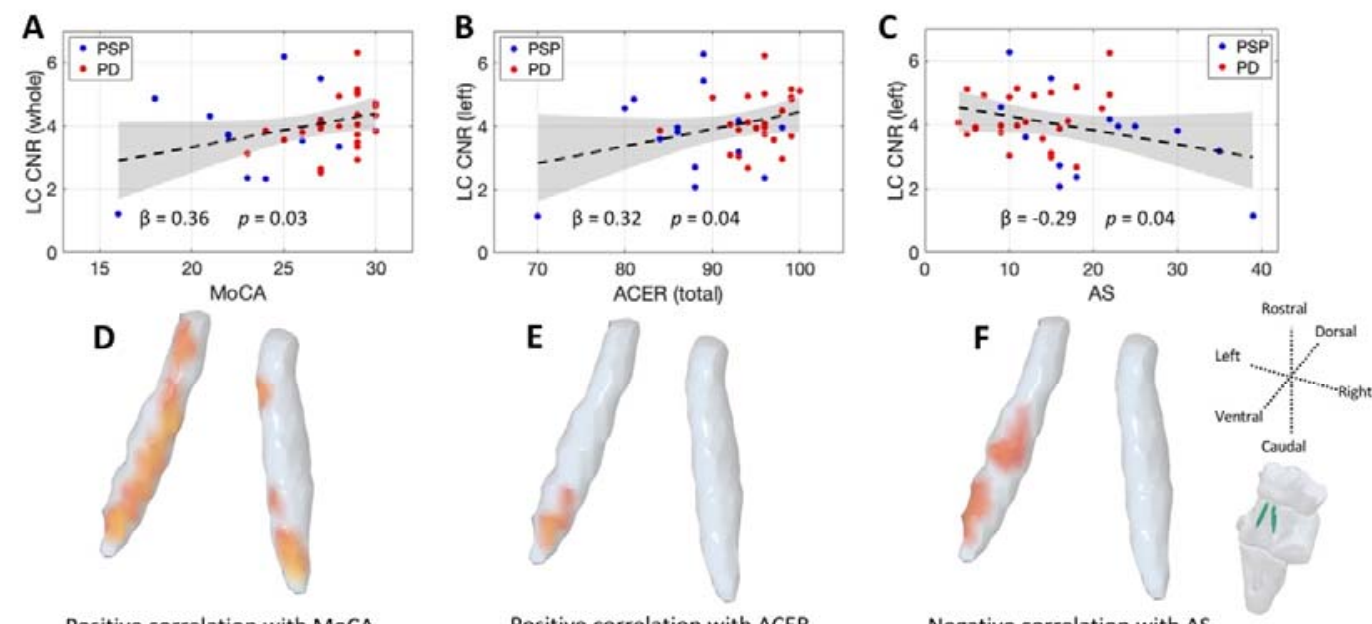

Positive correlation with MoCA

Positive correlation with ACER

Negative correlation with AS

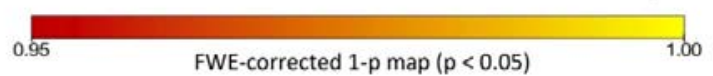


medRxiv preprint doi: https://doi.org/10.1101/2021.04.19.21255762; this version posted April 27, 2021. The copyright holder for this preprint (which was not certified by peer review) is the author/funder, who has granted medRxiv a license to display the preprint in perpetuity.

It is made available under a CC-BY 4.0 International license .

\section{Figure legends}

Figure 1 Comparisons of LC integrity across the three groups. Group averaged axial MT images coregistered with the ICBM152 standard template were presented (A) where diminished LC (arrows pointing to) signal can be seen in both PD and PSP patients. The rostrocaudal distributions (top: rostral, bottom: caudal) of LC CNR $(B)$ calculated against a reference region (REF in $A)$ in the pontine tegmentum area depicted a rostrocaudal gradient of the contrast reduction in disease groups. The voxelwise analyses further confirmed LC clusters with significant contrast reduction in right caudal LC for PD (C) and bilateral caudal LC for PSP (D) compared to controls (threshold free cluster enhancement, 10,000 permutations, FWE-corrected $p<0.05)$.

Figure 2 The role of $L C$ in global cognition and apathy. The MoCA (A), ACE-R (B) and AS Apathy score $(C)$ in PD and PSP correlate with LC contrast. The fitted regression line and $95 \%$ confidence interval (shaded area) are presented. The spatial distributions within the LC contributing to global cognition and apathy are revealed from voxelwise regression models (D-F, threshold free cluster enhancement, 10,000 permutations, FWE-corrected p<0.05). 